\title{
Ten-year experience with single-vessel and multivessel reoperative off-pump coronary artery bypass grafting
}

Yugal K. Mishra, PhD, Sathiakar Paul Collison, DNB, Rajneesh Malhotra, MCh, Vijay Kohli, MCh, Yatin Mehta, MD, and Naresh Trehan, MD

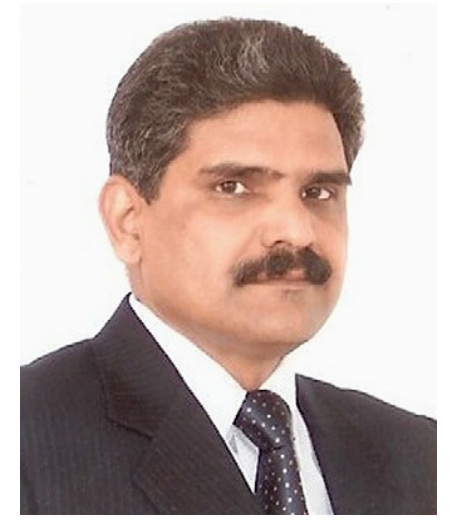

Dr Mishra
From Escorts Heart Institute and Research Centre, New Delhi, India.

Received for publication April 28, 2007; revisions received Oct 5, 2007; accepted for publication Oct 19, 2007.

Address for reprint: Yugal K. Mishra, PhD, Escorts Heart Institute and Research Centre, Okhla Road, New Delhi 110025, India (E-mail: dryugal@yahoo.com).

J Thorac Cardiovasc Surg 2008;135:527-32 0022-5223/ $\$ 34.00$

Copyright $(2008$ by The American Association for Thoracic Surgery

doi:10.1016/j.jtcvs.2007.10.019
Objective: Patients undergoing reoperative coronary artery bypass have increased mortality and morbidity compared with those undergoing primary coronary bypass. The experience in applying off-pump techniques to coronary reoperations is limited. In this article we report a 10-year experience using various techniques of reoperative off-pump coronary bypass.

Methods: Between January 1996 and December 2005, 332 patients underwent reoperative off-pump coronary artery bypass grafting. Data were collected regarding the preoperative, intraoperative, and postoperative clinical course of all patients. These were compared with similar data obtained from patients who had undergone conventional coronary reoperation during this period.

Results: Two hundred ninety-six (89.2\%) male and 36 female patients underwent reoperative off-pump coronary artery bypass. Of these, 265 (79.8\%) patients underwent multivessel bypass through a median sternotomy, an anterolateral thoracotomy was performed in $63(19 \%)$ patients, and a posterolateral thoracotomy was performed in $4(1.2 \%)$ patients. The early mortality for patients undergoing off-pump surgery was lower than for those undergoing conventional reoperations $(3.3 \%$ vs $5.5 \%, P=$ .066). Those who had undergone off-pump reoperations had less need for prolonged ventilation or prolonged inotropic support and had shorter intensive care unit and hospital stays than patients who had undergone redo coronary artery bypass grafting.

Conclusion: For many patients requiring coronary reoperations, off-pump techniques are safe and feasible. Complete revascularization was achieved in at least $75 \%$ of patients in an unselected population, with mortality and perioperative event rates that are comparable with those of conventionally performed coronary reoperations.

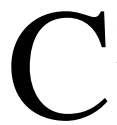
oronary artery bypass grafting $(\mathrm{CABG})$ is a well-established therapy for patients with coronary artery disease, and the results of primary operations are relatively good. However, many patients have recurrent symptoms, and some require reoperation. Although some authors have observed similar rates of mortality and morbidity for both primary coronary artery surgery and reoperative coronary bypass, ${ }^{1}$ many other groups have found that mortality and morbidity are higher during coronary reoperation. ${ }^{2,3}$ Traditionally, coronary reoperation has been performed during cardiopulmonary bypass with the aorta crossclamped and the heart arrested by means of cardioplegia (redo CABG). Recently, techniques of performing coronary artery surgery off pump have been developed. At this institution, we are routinely performing primary off-pump CABG $(\mathrm{OPCABG}),{ }^{4}$ with excellent results. ${ }^{5}$ The reports of the application of off-pump techniques to coronary reoperations (redo OPCABG) for either single-vessel or multivessel disease are few. ${ }^{6-10}$ The aim of this retrospective study was to analyze our experience with redo OPCABG.

\section{Materials and Methods Study Population}

From January 1996 until December 2005, reoperative coronary artery bypass was performed on 538 patients at this institution. Of these, 332 underwent redo OPCABG, of whom $296(89.2 \%)$ 


\section{Abbreviations and Acronyms \\ $\mathrm{CABG}=$ coronary artery bypass grafting \\ LAD $\quad=$ left anterior descending coronary artery \\ LITA $=$ left internal thoracic artery \\ $\mathrm{OPCABG}=$ off-pump coronary artery bypass grafting}

were male and $36(10.8 \%)$ were female; these patients are the subject of this study. During this period, 206 patients (183 [88.8\%] male and 23 [11.2\%] female patients) underwent redo CABG. The different surgical approaches, as well as the revascularization procedures, used in the redo OPCABG group are presented in Table 1. All patients had symptomatic coronary artery disease that could not be managed by using medical therapy. Apart from routine investigations, specific preoperative studies included coronary angiography, transthoracic echocardiography, pulmonary function testing, posteroanterior and lateral chest radiography, and, more recently, contrastenhanced computed tomography of the chest.

\section{Choice of Technique}

The selection of patients to receive redo OPCABG or redo CABG was left to the discretion of the operating surgeons, all of whom were experienced in both procedures. The factors influencing the decision to perform the procedure on pump included worse hemodynamic status, increased urgency of the operation, and worse quality of distal coronary target vessels.

\section{Selection of Surgical Approach}

Median sternotomy. All patients planned for multivessel revascularization underwent sternotomy.

Anterolateral thoracotomy. Anterolateral thoracotomy was used as a technique to avoid the morbidity of sternal re-entry, especially in sicker, often older patients with additional comorbidities who required left anterior descending coronary artery (LAD) bypass, and as an elective, minimally invasive procedure for those who required LAD grafting.

Posterolateral thoracotomy. Posterolateral thoracotomy was used for grafting the obtuse marginal vessels in patients with patent left internal thoracic artery (LITA)-LAD grafts.

\section{Surgical Technique}

Median sternotomy was the surgical approach used in 265 cases. The redo sternotomy and mediastinal dissection were performed as recommended previously, ${ }^{11}$ essentially by using an oscillating saw, initial exposure of the aorta and right atrium, the "no-touch" technique for previously placed grafts, and careful progression of the dissection on the left ventricle to identify and preserve previously placed thoracic artery-coronary artery grafts. The entire heart was mobilized in all cases. Indications for conversion to redo CABG included bleeding at sternal re-entry, hemodynamic instability during mediastinal dissection, or the finding of small-caliber, diffusely diseased coronary targets, rendering off-pump methods technically difficult. The patient was given $3 \mathrm{mg} / \mathrm{kg}$ heparin. To facilitate distal anastomosis, use was made of commercially available suction-based cardiac stabilization devices, and a $\mathrm{CO}_{2}$ blower and intraluminal shunts were used routinely. The proximal aortic anastomoses were
TABLE 1. Operative details of patients undergoing redo OPCABG

\begin{tabular}{lc} 
Median sternotomy $(\mathbf{n}=\mathbf{2 6 5})$ & \\
Mean no. of grafts per patient & $2.17 \pm 0.74$ \\
No. of grafts & \\
1 & $71(26.7 \%)$ \\
2 & $87(32.9 \%)$ \\
3 & $98(37 \%)$ \\
4 & $9(3.4 \%)$ \\
Conduits & \\
LITA & $151(56.8 \%)$ \\
RSVG & $212(80 \%)$ \\
Radial artery & $119(6.3 \%)$ \\
RGEA & $1(0.3 \%)$ \\
Intraoperative IABP insertion & $21(8 \%)$ \\
Need for CPB & $29(11 \%)$ \\
Anterolateral thoracotomy $(\mathbf{n}=\mathbf{6 3})$ & \\
LITA-LAD & $55(83.3 \%)$ \\
LITA-LAD + PTCA & $4(6.3 \%)$ \\
LITA-LAD + TMLR & $4(6.3 \%)$ \\
Posterolateral thoracotomy (n= 4) & \\
RSVG-OM & $4(6.3 \%)$ \\
\hline
\end{tabular}

OPCABG, Off-pump coronary artery bypass grafting; LITA, left internal thoracic artery; $R S V G$, reverse saphenous venous graft; $R G E A$, right gastroepiploic artery; $I A B P$, intra-aortic balloon pump; $C P B$, cardiopulmonary bypass; $L A D$, left anterior descending coronary artery; $P T C A$, percutaneous coronary angioplasty; $T M L R$, transmyocardial laser revascularization; $O M$, obtuse marginal.

performed by using a partial, side-biting, atraumatic vascular clamp. The effects of heparin were reversed with protamine, and graft flows were checked with Doppler probes. The redo CABG procedure was performed during aortic crossclamping with both antegrade and retrograde delivery of cold blood (4:1) cardioplegia, moderate systemic hypothermia, and a terminal hot shot.

Anterolateral thoracotomy. After institution of double-lumen endotracheal intubation, the patient was placed in the right lateral decubitus position with the pelvis externally rotated to $45^{\circ}$ to allow access to the femoral artery. A small skin incision was made along the fifth intercostal space between the nipple and the midaxillary line, and the fifth intercostal space was opened. The thoracotomy was extended anteriorly or posteriorly to facilitate the operation. With the lung deflated, the LITA was harvested, as described elsewhere. ${ }^{12}$ The pericardium was then opened anterior to the phrenic nerve. Limited adhesiolysis, sufficient to expose the target vessels, was performed, and then the anastomosis was performed by using standard techniques.

Posterolateral thoracotomy. The fifth intercostal space was used to enter the chest. The pericardium was palpated to locate and avoid old vein grafts if present and was opened posterior to the phrenic nerve. After distal anastomosis, proximal anastomosis was performed on the descending aorta by routing the grafts anterior to the pulmonary hilum.

Data were collected regarding the preoperative, intraoperative, and postoperative clinical course of all patients. The operative notes were used to evaluate the choice and number of grafts. Perioperative myocardial infarction was defined as any new $\mathrm{Q}$ wave or loss of $\mathrm{R}$ wave on the electrocardiogram or a significant increase in creatine kinase-myocardial fraction levels $(>40 \mathrm{U} / \mathrm{L})$. Postoperative 
bleeding was defined as the need for re-exploration for persistent bleeding. Cerebrovascular accident was defined as a coma lasting longer than 24 hours, transient ischemic attack, or neurologic deficit lasting longer than 72 hours. Renal failure includes both an increase of serum creatinine value to twice preoperative levels and a need for dialysis. The patients who required intraoperative conversion from redo OPCABG to redo CABG were included in the redo $\mathrm{CABG}$ group for final analysis.

Statistical analysis was performed with SPSS software (SPSS, Inc, Chicago, Ill). All clinical data are expressed as means \pm standard deviations. Categorical values were compared by means of the $\chi^{2}$ test, and the Mann-Whitney test was used to calculate the differences in continuous variables between the 2 groups. The mean number of grafts per patient in each group was compared by using the paired Student $t$ test.

The use of these data for research was approved by the institutional review board.

\section{Results}

Feasibility of Redo OPCABG

Five hundred thirty-eight patients had coronary reoperations during the 10-year study period. Of these, 332 (61.7\%) underwent redo OPCABG, with 265 (79.8\%) patients undergoing bypass through a median sternotomy, 63 (19\%) patients undergoing bypass though an anterolateral thoracotomy, and $4(1.2 \%)$ patients undergoing posterolateral thoracotomy (Table 1). The preoperative characteristics of this unselected patient population (Table 2) reveal that redo OPCABG is feasible in most patients, regardless of the coexisting disease or the urgency of clinical presentation. Note that $35.5 \%$ required urgent operations, $7.6 \%$ had an intra-aortic balloon pump, and $16 \%$ had significant left main disease. Preoperatively planned redo OPCABG required intraoperative conversion to redo CABG in only $11 \%$ of cases, and in only $8 \%$ of cases was institution of intra-aortic balloon pump support needed. There was no difference in outcome between patients requiring intraoperative conversion to redo $\mathrm{CABG}$ and those preoperatively selected for redo CABG. An average of 2.17 grafts per patient could be placed in those requiring multivessel bypass, with 57\% receiving LITA-LAD anastomoses (Table 3). In the group undergoing anterolateral thoracotomy, all 68 patients received LITA-LAD grafts without the need for cardiopulmonary bypass.

\section{Safety of Redo OPCABG}

Hospital mortality was $3.3 \%$ (11 patients) in the median sternotomy group (Table 4), and 1 patient died after anterolateral thoracotomy. In the multivessel redo OPCABG group, morbidity also was low: postoperative myocardial infarction, 4.8\%; renal failure, $0.6 \%$; cerebrovascular accident, $0 \%$; and prolonged ventilation, $7.5 \%$.

\section{Discussion}

The large number of isolated primary $\mathrm{CABG}$ procedures performed in the 1980s and 1990s increased the incidence
TABLE 2. Preoperative characteristics

\begin{tabular}{lcc}
\hline \multicolumn{1}{c}{ Variable } & $\begin{array}{c}\text { Redo OPCABG } \\
\text { (n = 332) }\end{array}$ & $\begin{array}{c}\text { Redo CABG } \\
\text { (n = 206) }\end{array}$ \\
\hline Age (y \pm SD) & $60.4 \pm 5.8$ & $61.2 \pm 6.1$ \\
Female sex (\%) & $36(10.8 \%)$ & $23(11.2 \%)$ \\
Unstable angina & $116(34.9 \%)$ & $89(43.2 \%)$ \\
Previous myocardial infarction & $153(46.1 \%)$ & $101(49 \%)$ \\
Congestive heart failure & $23(6.9 \%)$ & $10(4.9 \%)$ \\
Peripheral vascular disease & $19(5.7 \%)$ & $7(3.4 \%)$ \\
Aortic atheroma & $28(8.4 \%)$ & $15(7.3 \%)$ \\
Prior cerebrovascular accident & $12(3.6 \%)$ & $5(2.4 \%)$ \\
Chronic obstructive pulmonary disease & $25(7.5 \%)$ & $17(8.2 \%)$ \\
Renal failure & $5(1.5 \%)$ & $3(1.4 \%)$ \\
Diabetes & $108(32.5 \%)$ & $64(31.1 \%)$ \\
Hypertension & $159(47.9 \%)$ & $108(52.4 \%)$ \\
Smoker & $55(16.6 \%)$ & $35(17 \%)$ \\
Interval from previous bypass (mo) & $89 \pm 17$ & $79 \pm 14$ \\
Previous use of LITA & $101(30.8 \%)$ & $68(33 \%)$ \\
Preoperative intra-aortic balloon pump & $26(7.8 \%)$ & $19(9.2 \%)$ \\
Emergency operation & $118(35.5 \%)$ & $91(44.2 \%)$ \\
Preoperative ejection fraction & $42.6 \pm 6.8$ & $43.1 \pm 6.6$ \\
$\quad$ (mean \pm SD) & & \\
Vessels diseased & & \\
$\quad$ Single & $5(1.5 \%)$ & $0(0 \%)$ \\
Double & $56(16.9 \%)$ & $38(18.5 \%)$ \\
Triple & $271(81.6 \%)$ & $168(81.5 \%)$ \\
Left main disease & $53(16 \%)$ & $44(21.4 \%)$ \\
\hline OPCABG & & \\
\hline
\end{tabular}

$O P C A B G$, Off-pump coronary artery bypass grafting; $C A B G$, coronary artery bypass grafting; $S D$, standard deviation; $L I T A$, left internal thoracic artery.

of patients requiring reoperative coronary bypass in these decades. ${ }^{3}$ In recent years, however, the number of patients undergoing coronary reoperation has reached a plateau in some institutions (Figure 1). ${ }^{1,2}$ This is the result of routine use of the LITA for grafting of the LAD, better management

TABLE 3. Operative details of the patients undergoing median sternotomy

\begin{tabular}{|c|c|c|c|}
\hline Variable & $\begin{array}{l}\text { Redo OPCABG } \\
\quad(n=265)\end{array}$ & $\begin{array}{c}\text { Redo CABG } \\
(n=206)\end{array}$ & $P$ value \\
\hline $\begin{array}{l}\text { Mean grafts per patient } \\
\text { No. of grafts }\end{array}$ & $2.17 \pm 0.74$ & $2.51 \pm 0.66$ & .265 \\
\hline 1 & $71(26.7 \%)$ & $17(8.3 \%)$ & .065 \\
\hline 2 & $87(32.9 \%)$ & $78(37.9 \%)$ & .213 \\
\hline 3 & $98(37 \%)$ & $101(49.0 \%)$ & .311 \\
\hline 4 & $9(2.7 \%)$ & $10(4.8 \%)$ & .756 \\
\hline \multicolumn{4}{|l|}{ Conduits } \\
\hline LITA & $151(56.8 \%)$ & $125(60.6 \%)$ & .673 \\
\hline Radial artery & $119(44.9 \%)$ & $156(75.7 \%)$ & .05 \\
\hline RSVG & $212(80 \%)$ & $195(94.7 \%)$ & .686 \\
\hline RGEA & $2(0.6 \%)$ & $1(0.5 \%)$ & 1.00 \\
\hline
\end{tabular}

OPCABG, Off-pump coronary artery bypass grafting; $C A B G$, coronary artery bypass grafting; $L I T A$, left internal thoracic artery; $R S V G$, reverse saphenous vein graft; $R G E A$, right gastroepiploic artery. 
TABLE 4. Postoperative outcomes

\begin{tabular}{lcc}
\hline \multicolumn{1}{c}{ Outcome } & Redo OPCABG & Redo CABG \\
\hline Mortality & $11(3.3 \%)$ & $12(5.8 \%)$ \\
CVA & $0(0.0 \%)$ & $3(1.4 \%)$ \\
Postoperative MI & $16(4.8 \%)$ & $15(7.3 \%)$ \\
Postoperative bleeding & $7(2.1 \%)$ & $9(4.4 \%)$ \\
Atrial fibrillation & $12(3.6 \%)$ & $16(7.8 \%)$ \\
Renal failure & $2(0.6 \%)$ & $5(2.4 \%)$ \\
Patients requiring transfusions (\%) & $46(13.6 \%)$ & $173(84 \%)$ \\
Prolonged ventilation $(>24 \mathrm{~h})$ & $25(7.5 \%)$ & $35(17 \%)$ \\
Need for inotropes $>48 \mathrm{~h}$ & $38(11.4 \%)$ & $49(23.8 \%)$ \\
ICU stay (h) & $21 \pm 4$ & $38 \pm 6$ \\
Hospital stay (d) & $5 \pm 3$ & $9 \pm 4$ \\
\hline
\end{tabular}

$O P C A B G$, Off-pump coronary artery bypass grafting; $C A B G$, coronary artery bypass grafting; $C V A$, cerebrovascular accident; $M I$, myocardial infarction; $I C U$, intensive care unit.

of saphenous venous conduits, and evolution in antiplatelet and statin therapy. Hence patients who require coronary reoperations are currently older, with more extensive coronary artery disease and poorer left ventricular function. ${ }^{2}$

Despite technical improvements and increased surgical experience, most series of coronary reoperations report higher rates of mortality and morbidity compared with primary operations, in the range of $4 \%$ to $16 \% .^{13}$ There are several factors that contribute to this: hazards during sternal re-entry, hemodynamic instability during mediastinal dissection, inadvertant damage to patent grafts, ischemia caused by embolization of atheromatous debris from venous conduits, and inadequate myocardial protection caused by difficulties in delivering cardioplegia in the face of native and conduit stenoses. Additionally, parallel to progression of coronary artery disease, there might be more extensive aortic atherosclerotic disease. ${ }^{14}$

OPCABG aims at complete revascularization without subjecting the patient to the ill effects of extracorporeal circu-

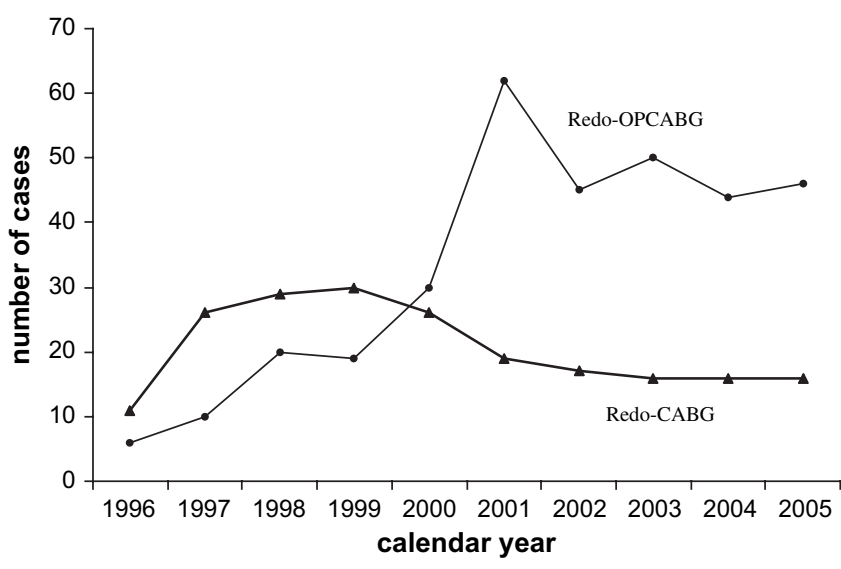

Figure 1. Depiction of the increasing trend toward redo off-pump coronary artery bypass grafting (OPCABG) at this institution. $C A B G$, Coronary artery bypass grafting. lation, cardioplegia, or aortic cannulation. Some benefits of OPCABG over CABG at primary operation have been noted: decreased incidence of atrial fibrillation, transfusion needs, inotrope requirements, respiratory infections, ventilation time, intensive care unit stay, and hospital stay. ${ }^{15}$ However, concerns regarding the completeness of revascularization and graft patency remain.

There are few published reports of the application of offpump techniques to coronary reoperations. Many of these pertain to single-vessel coronary targets, ${ }^{16,17}$ and experience with multivessel redo OPCABG is limited. ${ }^{6-9}$

This report documents the largest and most comprehensive experience of the use of off-pump techniques for reoperative coronary artery bypass. Compared with patients usually encountered in North America, our patient cohort is younger and thus perhaps at less risk during coronary reoperation, and this fact could have influenced our results. Nonetheless, although this is a retrospective and nonrandomized study in which surgeons selected the choice of procedure, we believe that the large and unselected patient population described helps to establish the safety and feasibility of redo OPCABG for routine clinical use.

\section{Safety and Feasibility}

We have shown that redo OPCABG can be performed safely in $61.7 \%$ of patients presenting for coronary reoperation, regardless of the comorbid disease, and in a wide range of clinical presentations of the patient. The overall mortality of $3.3 \%$ in our patients compares favorably with that of most published studies on conventionally performed coronary reoperation. Sabik and colleagues ${ }^{1}$ reported a mortality rate of $4.4 \%$ for their patients undergoing first reoperation; Di Mauro and associates ${ }^{7}$ reported that their mortality rate was $4.2 \%$. We have also found that among our patients, the performance of redo OPCABG results in low rates of perioperative myocardial infarction, renal failure, and cerebrovascular accidents and allows for reasonably swift recovery of these patients. The present study was not designed to be a true comparison of outcome between redo OPCABG and redo CABG. We sought to establish the safety and efficacy of redo OPCABG in a large series of patients undergoing coronary reoperation, especially in light of the limited worldwide experience with this technique. The comparison presented sheds some light on the spectrum of cases that can be performed safely by using off-pump techniques. However, other authors have compared redo OPCABG with redo $\mathrm{CABG}$ directly. ${ }^{6-9}$ In all of these studies, the trend is toward a reduction in mortality and morbidity in the redo OPCABG groups. It merits emphasis, however, that in all of these studies, patients were not randomized to receive either procedure, and criteria for selection for redo OPCABG was variable. Moreover, these were small studies, and hence these trends have not become statistically significant. Recently, blood transfusion requirements have been shown to 
be reduced when redo OPCABG is performed. ${ }^{18}$ None of the studies could show a significant difference in atrial fibrillation, renal function, cerebrovascular accident, or other minor adverse clinical parameters.

\section{Adequateness of Revascularization}

Complete revascularization is the main goal of primary coronary bypass, and it is reasonable to assume the same is true of coronary reoperation. Studies have demonstrated that incomplete myocardial revascularization negatively affects outcome after primary operations. ${ }^{19}$ The main concerns regarding primary OPCABG involve completeness of revascularization achieved and graft patency. In the setting of coronary reoperation, Di Mauro and associates ${ }^{7}$ found higher rates of incomplete revascularization in patients undergoing redo OPCABG $(17.7 \%$ vs $5.9 \%, P<.01)$ when compared with redo $\mathrm{CABG}$ and showed that incomplete revascularization was an independent risk factor for cardiac death and cardiac mortality at 5 years. Tugtekin and coworkers ${ }^{8}$ used the index of completeness of revascularization (preoperative planned/ performed anastomosis) to compare redo $\mathrm{CABG}$ and redo OPCABG. They found a higher incidence of complete revascularization in their redo $\mathrm{CABG}$ group $(86.9 \%$ for redo $\mathrm{CABG}$ vs $48.6 \%$ for redo OPCABG, $P<.01$ ). In the study by Czerny and colleagues, ${ }^{6}$ in which redo OPCABG was targeted to culprit coronary targets (target vessel revascularization), because of significant difference in completeness of revascularization, a higher incidence of recurrent angina was noted during a 5-year follow-up period. From these studies, there is some evidence of less complete revascularization when performing coronary reoperations by using off-pump techniques.

The application of a thoracotomy approach toward coronary reoperations appears to be more accepted. ${ }^{20,21}$ After primary bypass, progression of disease and venous graft attrition often lead to a situation in which a reoperative bypass is required in the presence of patent internal thoracic artery grafts. The posterolateral thoracotomy approach allows revascularization of the obtuse marginal vessels while avoiding the hazards of sternal re-entry, with its potential for injury to the patent grafts. Additionally, in cases in which a vein graft might have been placed on the LAD during the first operation, the anterolateral thoracotomy approach allows LITA-LAD grafting without sternal re-entry. Furthermore, this approach also allows for the performance of hybrid revascularization safely, as well as transmyocardial laser revascularization. ${ }^{22}$

Certain limitations of this study must be addressed. This was a nonrandomized retrospective study that has allowed the feasibility of redo OPCABG to be established. However, a true comparison of redo OPCABG with redo CABG would require a randomized controlled trial with well-defined criteria for selection of patients for redo OPCABG. These studies are necessary to obtain evidence as to which preoperative factors could predict preoperatively that a patient would have a successful off-pump procedure.
In summary, this report describes the versatility of the various techniques of redo OPCABG and demonstrates that for a majority of patients requiring coronary reoperations, off-pump techniques are safe and feasible. Complete revascularization was achieved in at least $75 \%$ of patients in an unselected population, with mortality and perioperative event rates that are comparable with those of conventionally performed coronary reoperation.

\section{References}

1. Sabik JF 3rd, Blackstone EH, Houghtaling PL, Walts PA, Lytle BW. Is reoperation still a risk factor in coronary artery bypass surgery? Ann Thorac Surg. 2005;80:1719-27.

2. Yau TM, Borger MA, Weisel RD, Ivanov J. The changing pattern of reoperative coronary surgery: trends in 1230 consecutive reoperations. J Thorac Cardiovasc Surg. 2000;120:156-63.

3. Van Eck FM, Noyez L, Verheugt FWA, Brouwer RMHJ. Changing profile of patients undergoing redo-coronary artery surgery. Eur J Cardiothorac Surg. 2002;21:205-11.

4. Meharwal ZS, Mishra YK, Kohli V, Singh S, Bapna RK, Mehta YM, et al. Multivessel off-pump coronary artery bypass: analysis of 4953 cases. Heart Surg Forum. 2003;6:153-9.

5. Mishra M, Malhotra R, Karlekar A, Mishra Y, Trehan N. Propensity case-matched analysis of off-pump versus on-pump coronary artery bypass grafting in patients with atheromatous aorta. Ann Thorac Surg. 2006;82:608-14.

6. Czerny M, Zimpfer D, Kilo J, Gottadi R, Duynkler D, Wolner E, et al. Coronary reoperations: recurrence of angina and clinical outcome with and without cardiopulmonary bypass. Ann Thorac Surg. 2003;75:847-52.

7. Di Mauro M, Iaco AL, Contini M, Teodari G, Vittolla G, Pano M, et al. Reoperative coronary artery bypass grafting: analysis of early and late outcomes. Ann Thorac Surg. 2005;79:81-7.

8. Tugtekin SM, Alexiou K, Kappert U, Esche H, Joskowiak D, Knaut M, et al. Coronary reoperation with and without cardiopulmonary bypass. Clin Res Cardiol. 2006;95:93-8.

9. Morris CD, Puskas JD, Pusca SV, Lattouf OM, Cooper WA, Vassiliades TA, et al. Outcomes after off-pump reoperative coronary artery bypass grafting. Innovations. 2007;2:29-32.

10. Dewey TM, Magee MJ, Acuff T, Prince S, Herbert M, Edgerton JR, et al. Beating heart surgery reduces mortality in the reoperative bypass patient. Heart Surg Forum. 2002;5(suppl 4):S301-16.

11. Craver JM, Hodakowski GT, Shen Y, Wientraub WS, Accola KD, Guyton RA, et al. Third-time coronary artery bypass operations: surgical strategy and results. Ann Thorac Surg. 1996;62:1801-7.

12. Calafiore AM, Di Giammarco GD, Teodori G, Bosco G, D’Annunzio E, Barsotti A, et al. Left anterior descending coronary artery grafting via left anterior small thoracotomy without cardiopulmonary bypass. LAST operation. Ann Thorac Surg. 1996;61:1658-65.

13. Kaul TK, Fields BL, Wyatt DA, Jones CR, Kahn DR. Reoperative coronary artery bypass surgery: early and late results and management in 1300 patients. J Cardiovasc Surg. 1995;36:303-3.

14. Noyez L, van Eck FM. Long-term cardiac survival after reoperative coronary artery bypass grafting. Eur J Cardiothorac Surg. 2004;25: 59-64.

15. Cheng DC, Bainbridge D, Martin JE, Novick RJ. Does off pump coronary artery bypass reduce mortality, morbidity and resource utilization when compared to conventional coronary artery bypass? A meta-analysis of randomised trials. Anesthesiology. 2005;102:188-203.

16. Allen KB, Matheny RG, Robison RJ, Heimansohn DA, Shaar CJ. Minimally invasive versus conventional reoperative coronary artery bypass. Ann Thorac Surg. 1997;64:616-22.

17. Stamou SC, Pfister AJ, Dangas G, Dullum MK, Boyce SW, Bafi AS, et al. Beating heart versus conventional single-vessel reoperative coronary artery bypass. Ann Thorac Surg. 2000;69:1383-7.

18. Gerli C, Mantovani L, Franco A, De Luca M, Bergonzi PC, Romano A, et al. Redo coronary artery bypass grafting on the beating heart and transfusion needs. Minerva Anestesiol. 2006;72:985-93. 
19. Caputo M, Reeves BC, Rajkaruna C, Awair H, Angelini GD. Incomplete revascularization during OPCAB surgery is associated with reduced mid-term event-free survival. Ann Thorac Surg. 2005;80:2141-7.

20. Azoury FM, Gillinov AM, Lytle BW, Smedira NG, Sabik JF. Offpump reoperative coronary artery bypass grafting by thoracotomy patient selection and operative technique. Ann Thorac Surg. 2001; 71:1959-63.
21. Shapira OM, Natarajan V, Kaushik S, DeAndrade KM, Shemin RJ. Off-pump versus on-pump reoperative CABG via a left thoracotomy for circumflex coronary artery revasularisation. J Card Surg. 2004; 18:113-8.

22. Gregoric I, Messner G, Couto WJ, Sartori M, Cervera R, Kadipasaoglu $\mathrm{K}$, et al. Off-pump coronary artery bypass grafting and transmyocardial laser revascularisation via left thoracotomy. Tex Heart Inst J. 2003;30:13-8.

\section{Interactive eLearning Activities \\ http://learning.ctsnet.org}

The Joint Council on Thoracic Surgery Education was pleased to introduce a series of unique eLearning activities to CTSNet users at the AATS annual meeting in Philadelphia. Sponsored by several cardiothoracic surgical groups, this exciting new educational tool contains narrated videos of actual surgical procedures followed by a series of questions and an evaluation to earn Continuing Medical Education credit.

\footnotetext{
* Diagnosis and Management of Complications of Mitral Valve Repair

* Off Pump Coronary Artery Bypass

* OPCAB Debriefing

* Pediatric Cardiopulmonary Bypass Emergency Situations
}

\section{Experience these new educational tools today and provide us with your feedback. Go to: http://learning.ctsnet.org}

William E. Baumgartner, Chair

Joint Council on Thoracic Surgery Education

$$
\begin{gathered}
\text { Sponsored By: } \\
\text { American Association for Thoracic Surgery } \\
\text { The Society of Thoracic Surgeons } \\
\text { European Association for Cardio-Thoracic Surgery } \\
\text { Children's Memorial Hospital }
\end{gathered}
$$

